CORRECTION

\title{
Correction: Striatal dopaminergic alterations in individuals with copy number variants at the 22q11.2 genetic locus and their implications for psychosis risk: a [18F]-DOPA PET study
}

Maria Rogdaki (D), Céline Devroye, Mariasole Ciampoli, Mattia Veronese (D), Abhishekh H. Ashok (D), Robert A. McCutcheon (D), Sameer Jauhar (D), llaria Bonoldi, Maria Gudbrandsen (D), Eileen Daly (D), Therese van Amelsvoort, Marianne Van Den Bree (iD, Michael J. Owen (D), Federico Turkheimer (D), Francesco Papaleo (iD) and Oliver D. Howes

(c) The Author(s), under exclusive licence to Springer Nature Limited 2021

Molecular Psychiatry; https://doi.org/10.1038/s41380-021-01192-0

Correction to: Mol Psychiatry https://doi.org/10.1038/s41380-02101108-y

The original version of this article unfortunately contained a mistake. The spelling of the Abhishekh Ashok name was incorrect. The corrected name (Abhishekh $\mathrm{H}$. Ashok) is given below.
Abhishekh H. Ashok

The original article has been corrected. 